\title{
Prolonged Respiratory Failure Following Acute Myocardial Infarction: A Case Report
}

\author{
Gayatri G. Harshe ${ }^{a, b}$, Sushama K. Jotkar ${ }^{\mathrm{a}}$
}

\begin{abstract}
We have recently treated a case of acute anterior wall myocardial infarction who developed prolonged respiratory failure. The clinical details and possible mechanism are discussed.
\end{abstract}

Keywords: Respiratory failure; Acute myocardial infarction

\section{Introduction}

Pulmonary edema can be defined as an increase in lung fluid caused by extravasation of fluid from pulmonary vasculature into the interstitium and alveoli of the lungs. The build up of fluid leads to progressive deterioration of alveolar gas exchange and worsening of hypoxia [1].

The acute cardiogenic pulmonary edema is associated with damage of alveolo-capillary barrier [2]. Initially there is increase in plasma surfactant protein A and B, which represents the hydrostatic stress failure of alveolo-capillary barrier. Even after the hemodynamic abnormalities are resolved the prolonged elevation of hydrostatic stress further damages the barrier and accounts for the vulnerability of these patients for prolonged hypoxia [3].

\footnotetext{
Manuscript accepted for publication February 15, 2011


Kolhapur, Maharashtra, India

bCorresponding author: Gayatri G Harshe, "Shree" Plot no 43, Unit 2, Ambai defence colony, Sagarmal, Kolhapur 416008, Maharashtra, India. Email: soumeena@gmail.com
}

doi:10.4021/cr21e

\section{Case Report}

A 55-year-old female presented to the casualty of our hospital on 13th March 2010 in a gasping condition. She was referred to our hospital from another hospital where she was admitted on 9th March with acute anterior wall myocardial infarction (AWMI). She was not thrombolysed but was treated with tab. clopidogrel + aspirin $(75$ and $150 \mathrm{mg}$ ) for 3 days followed by tab isosorbide dinitrate $5 \mathrm{mg}$ tid, tab atorvastatin $10 \mathrm{mg}$ h.s., and inj enoxiparin (Lupinox) $0.4 \mathrm{ml}$ sc bid for 10 days. On March 15, 2010, she was shifted over to Isosorbide mononitrate $(30 \mathrm{mg})$ OD. During her stay at the other hospital it was noticed that she could not maintain her $\mathrm{O}_{2}$ saturation without nasal oxygen supplementation. She was a known case of bronchial asthma on inhalational steroid for the last 12 years.

On examination the patient was tachypnoeic, cyanosed, drowsy, and disoriented. Her pulse rate was 124 beats per minute, regular. The B. P. was $130 / 80 \mathrm{mmHg}$. There was moderate bronchospasm and a few bibasal crackles. She was intubated and put on ventilatory support. An X-ray of chest showed Lt. lower zone consolidation.

The results of laboratory investigations on admission were $\mathrm{Hb} 12.69 / \mathrm{dl}$, TLC 20,700/mm 3 (P 84\%, L 14\%, E 1\%, M $1 \%$ ), platelets $189,000 / \mathrm{mm}^{3}$, S. creatinine $1.4 \mathrm{mg} / \mathrm{dl}$, BUL 82 $\mathrm{mg} / \mathrm{dl}$, S. bilirubin $0.8 \mathrm{mg} / \mathrm{dl}$, total proteins $6.6 \mathrm{~g} / \mathrm{dl}$, albumin $3.6 \mathrm{~g} / \mathrm{dl}$, globulin $3.0 \mathrm{~g} / \mathrm{dl}$, SGOT $57 \mathrm{U} / \mathrm{L}$, SGPT $52 \mathrm{U} / \mathrm{L}$, alk. phospatase, $98 \mathrm{U} / \mathrm{L}$, S. sodium $149 \mathrm{mEq} / \mathrm{L}$, and S. potassium $4.8 \mathrm{mEq} / \mathrm{L}$. Two D Echo done on March 15, 2010, showed LVEF of $51 \%$ with apical hypokinesia. No clots, vegetations, or effusion were noted.BNP (19.310) was $784 \mathrm{pg} / \mathrm{ml}(\mathrm{N}=$ $0-100 \mathrm{pg} / \mathrm{ml}$ ). CPK (MB) 1st and 2nd readings were $19 \mathrm{IU} /$ $\mathrm{ml}$ and $29 \mathrm{IU} / \mathrm{ml}$ respectively. D-dimer was $650 \mathrm{ng} / \mathrm{ml}$, ANA (ELISA) borderline +ve, and ADA 5.0.ABG done on March 19, 2010 showed $\mathrm{pH}$ 7.398, $\mathrm{PaO}_{2} 24.1 \mathrm{mmHg}, \mathrm{PaCO}_{2} 72.6$ $\mathrm{mmHg}, \mathrm{HCO}_{3} 43.8 \mathrm{mEq} / \mathrm{L}, \mathrm{O}_{2}$ saturation $40.2 \%$. Findings of serial ECGs are tabulated (Table 1).

Blood sugar on admission was $231 \mathrm{mg} / \mathrm{dl}$. At discharge fasting and post prandial blood sugars were $135 \mathrm{mg} / \mathrm{dl}$ and $158 \mathrm{mg} / \mathrm{dl}$ respectively. S. creatinine was $1.6 \mathrm{mg} / \mathrm{dl}$. US KUB showed bilateral increased echogenecity of cortex. A 
Table 1. Serial ECG Changes

\begin{tabular}{lllll}
\hline D.M.Y & H.R. & Q wave & T wave & P wave \\
\hline 13.3 .10 & 100 & $\mathrm{~V}_{1}-\mathrm{V}_{3}$ & - & - \\
18.3 .10 & 80 & $\mathrm{~V}_{1}-\mathrm{V}_{2}$ & Inversion $\mathrm{V}_{1}-\mathrm{V}_{2}$ & - \\
24.3 .10 & 75 & $\mathrm{~V}_{1}-\mathrm{V}_{2}$ & Inversion $\mathrm{V}_{1}-\mathrm{V}_{2}$ & Tall 'p' \\
31.3 .10 & 60 & $\mathrm{~V}_{1}-\mathrm{V}_{2}$ & Inversion $\mathrm{V}_{1}-\mathrm{V}_{2}$ & Normal \\
13.4 .10 & 76 & $\mathrm{~V}_{1}-\mathrm{V}_{2}$ & Inversion $\mathrm{V}_{1}-\mathrm{V}_{2}$ & Normal \\
\hline
\end{tabular}

CT scan of brain was normal.

A diagnosis of acute left ventricular failure following AWMI with pneumonia and asthma was made. She was treated with inj augmentin $1.2 \mathrm{~g}$ iv bd, $\mathrm{x} 10 \mathrm{~d}$, moxifloxacin $400 \mathrm{mg}$ iv od x $10 \mathrm{~d}$, inj lasix $100 \mathrm{mg}$, stat followed by 40 mg od x $5 \mathrm{~d}$, inj deriphylline $2 \mathrm{ml}$ iv bd x $5 \mathrm{~d}$ followed by tab salbutamol $10 \mathrm{mg}$ od, duolin and budecort nebulization 6 hourly, inj hydrocortisone $100 \mathrm{mg}$ tid x $3 \mathrm{~d}$, and then tapered off over the next 4 days. Tab isosorbide mononitrate $30 \mathrm{mg}$ od was discontinued after 9 days.

Ventilatory support was withdrawn after 4 days (March $16,2010)$ and she was put on nasal oxygen. On discontinuation of the nasal support on 17th March she desaturated within 10 - 15 minutes and was tachypnoeic, dyspnoeic and cyanosed. Her $\mathrm{PaO}_{2}$ dropped to $30 \%$ - 35\%. This improved rapidly on reinstituting nasal $\mathrm{O}_{2}$. A repeat $2 \mathrm{D}$ Echo (March 19, 2010) revealed mild LV dysfunction and pulmonary artery pressure of $62 \mathrm{mmHg}$. An HRCT of chest with CT angiogram revealed diffuse patchy infiltrates involving both the lungs including apices (Fig. 1). There was no evidence of pulmonary embolism. Possibility of interstitial lung disease was considered and she was started on tab methylprednisolone $16 \mathrm{mg}$ bd. Over the next few days her tendency to and the rapidity of desaturation decreased progressively and after 4 weeks she could be totally weaned off oxygen support. A repeat HRCT scan done on 22nd April (5 weeks after admission) showed total resolution of the interstitial shadows (Fig. 2). During her hospital stay she had one episode of atrial

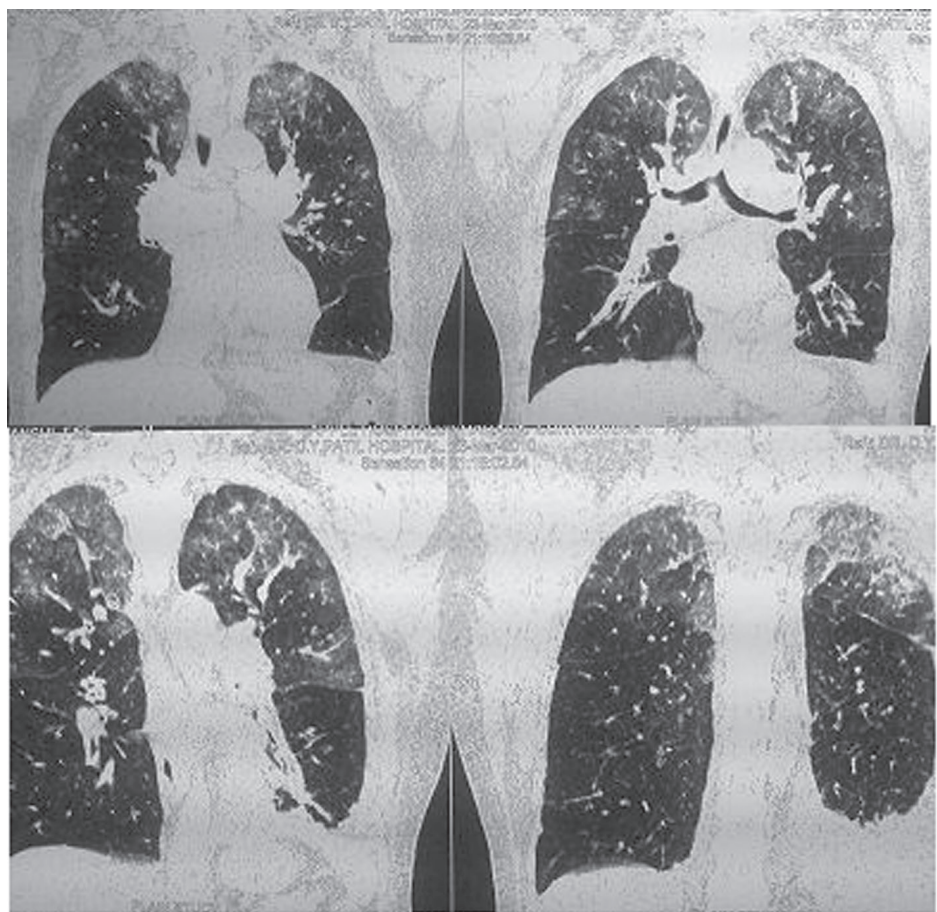

Figure 1. HRCT chest (23.03.2010) showing bilateral diffuse patchy infiltrates. 


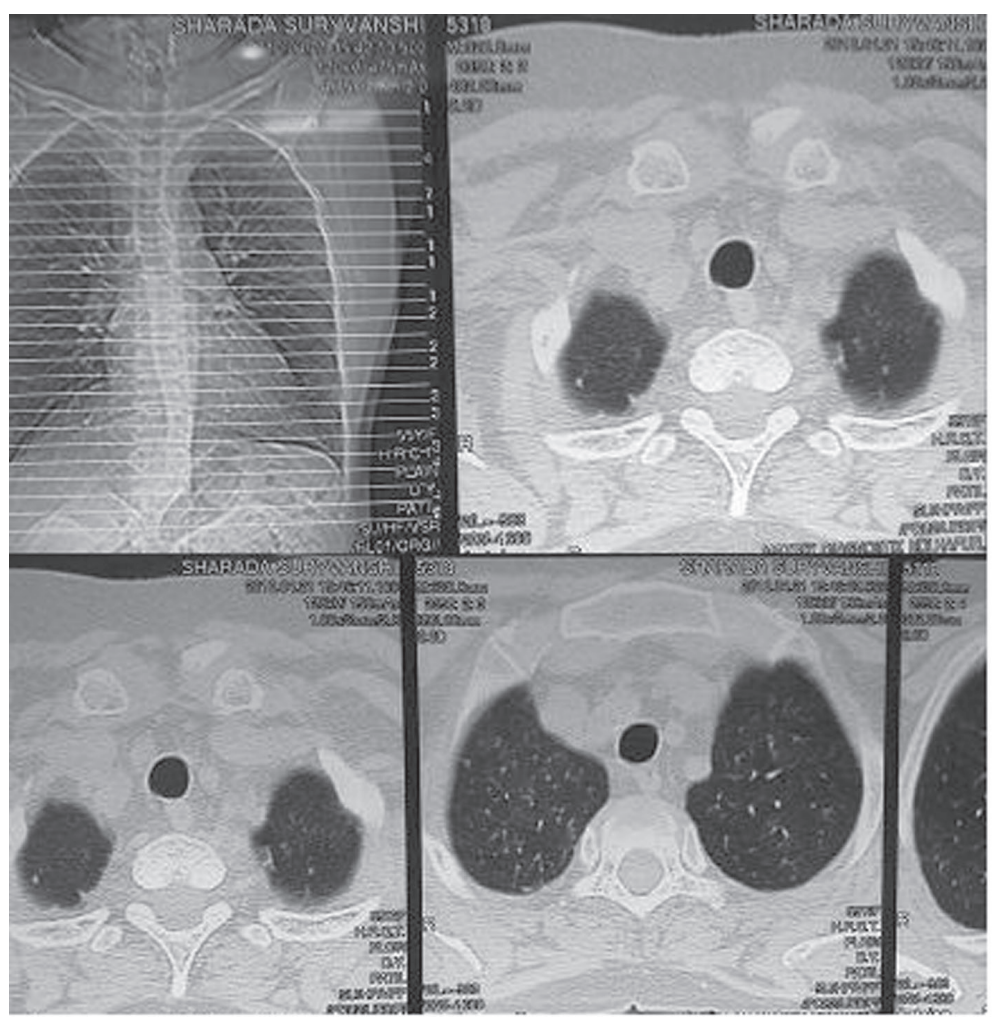

Figure 2. HRCT chest (22.04.2010) showing complete resolution of pulmonary shadows.

fibrillation that responded to tab diltiazem (30 mg tid). Her thyroid function tests suggested hyperthyroidism (TSH 0.09 $\mu \mathrm{IU} / \mathrm{ml}, \mathrm{T} 4-13.2 \mu \mathrm{g} / \mathrm{dl}, \mathrm{T} 32.2 \mathrm{ng} / \mathrm{ml}$ ) and she was started on neomercazole $5 \mathrm{mg}$ tid. The patient was discharged on 23rd April. She had no breathlessness or chest pain. Pulse and B.P. were normal. At follow up 10 days after discharge she was totally asymptomatic.

\section{Discussion}

Our patient's hospital stay was characterized by diffuse pulmonary pathology, with significant inability to maintain arterial oxygen saturation, along with $\mathrm{CO}_{2}$ retention. The most likely chain of events was anoxia secondary to "alveolocapillary block" [2] causing central respiratory depression, alveolar hypoventilation and $\mathrm{CO}_{2}$ retention.

It is important to speculate the possible cause of diffuse pulmonary pathology. The most plausible explanation is (interstitial) pulmonary edema secondary to LVF. However when nasal oxygen support was being withdrawn left ventricular failure was controlled; LVEF was 50\%.

Other causes of acute parenchymal lung disease are many, e.g. primary lung disorders, such as acute interstitial pneumonia, alveolar hemorrhage, fulminant cryptogenic or- ganizing pneumonia, hypersensitivity pneumonitis, and drug induced lung disease. On admission a diagnosis of pneumonia was made. She received antibiotics for the same. These were stopped when nasal oxygen discontinuation was attempted. There was no evidence of active infection at this point. Furthermore, recovery occurred without any further antibiotics. Infection therefore seems unlikely. Hypersensitivity pneumonitis can be considered especially because she was an asthmatic and was treated with methyl prednisolone which apparently helped her. Another mechanism could be muscular weakness. However, she had no evidences of muscle weakness. Ventilator induced diaphragmatic weakness is a possibility but the dramatic response to oxygen supplement would be unlikely with this pathology. Also we cannot ignore the evidence of pulmonary pathology.

Secondary causes of diffuse pulmonary pathology such as uremia, extensive progressive metastatic malignancy, and opportunistic infection are not applicable. Whatever her pulmonary pathology was, it was totally reversible and at discharge she was totally asymptomatic.

She did not have a CNS disorder to explain susceptibility to anoxic respiratory depression. This feature remains unexplained.

In summary we describe and discuss a patient who following acute anterior wall myocardial infarction had pro- 
longed inability to maintain adequate oxygenation while breathing ambient air. The possible mechanisms are discussed.

\section{References}

1. De Pasquale CG, Arnolda LF, Doyle IR, Grant RL, Ay- lward PE, Bersten AD. Prolonged alveolocapillary barrier damage after acute cardiogenic pulmonary edema. Crit Care Med 2003;31(4):1060-1067.

2. Mattu A, Martinez JP, Kelly BS. Modern management of cardiogenic pulmonary edema. Emerg Med Clin North Am 2005;23(4):1105-1125.

3. West JB, Mathieu-Costello O. Vulnerability of pulmonary capillaries in heart disease. Circulation 1995;92(3):622-631. 